Domain-based perceptions of risk

Pre-proof for Journal of Applied Psychology (accepted for publication, in press for 2013)

\title{
TITLE: Domain-based perceptions of risk: A case study of lay and technical community attitudes towards Managed Aquifer Recharge
}

Leviston, Z. ${ }^{a}$, Browne, A.L. ${ }^{b}$ \& Greenhill, M. ${ }^{a}$

a. CSIRO Sustainable Ecosystems, Private Bag, Wembley, Western Australia, 6913.

Ph: +61 89333 6169, Fax: +61 89383 7193, Email: zoe.leviston@csiro.au

b. The Lancaster Environment Centre, Lancaster University

\section{Abstract}

Despite growing water scarcity, communities in many parts of the developed world often reject technically and economically sound options for water augmentation. This paper reports findings from a study investigating risk perceptions associated with a proposed Managed Aquifer Recharge scheme in Australia. Q-Methodology was used to compare decision-making frameworks of lay community and 'technical expert' participants. Technical expert participants were also asked to approximate the decision-making framework of a 'typical' community member. The emerging contrasts between lay community frameworks and those approximated by technical experts suggest that there are prevailing yet errant assumptions about lay community attitudes towards new technologies. The findings challenge the characterisation of the lay community and technical experts as being in entrenched opposition with one another. 


\section{Introduction}

A growing demand for water, coupled with climate-change induced rainfall variability, has put pressure on governments and water utilities around the world to seek alternative ways of supplying water. An option often seen as a logical and viable way of supplementing water supply is the treatment and reuse of wastewater that would otherwise be discharged to oceans and rivers. Wastewater includes all waste water from domestic householders, and nonprescribed waste from industrial and agricultural sectors. The treatment and reuse of wastewater has traditionally been confined to non-potable purposes ${ }^{1}$ such as for irrigating public open space, for growing fruits and vegetables, and for a range of industrial purposes. Potable reuse schemes - those designed to augment drinking water supplies - are less common. Research has shown consistently that people's acceptance of using recycled water reduces as the

use becomes more personal or closer to human contact (e.g., Jeffrey \& Jefferson, 2003; Marks, Martin \& Zadoroznyj, 2006, 2008; Po, Kaercher \& Nancarrow, 2003). With regards to reuse schemes incorporating wastewater, community reactions are frequently and markedly different from reactions to reuse schemes that do not harness the waste stream, such as schemes harvesting stormwater and greywater (Hurlimann, 2007; Marks et al., 2006, 2008).

Despite the challenges facing potable reuse schemes, a number of successful projects exist, most notably in Singapore, Namibia and the United States

\footnotetext{
${ }^{1}$ Here we are referring to planned reuse schemes. Unplanned potable reuse is prevalent throughout the world; downstream withdrawal from the Thames River in London where wastewater is discharged upstream is one example.
} 
(Johnson, 2009; Landers, 2008; Public Utilities Board, 2008). Many of these reuse schemes were implemented in arid areas with significant water security issues. In Australia, where sparse water supplies and prolonged droughts are commonplace and where, under even the most modest climate change projections, rainfall will become less reliable (see CSIRO, 2007), proposed wastewater reuse schemes for household drinking purposes have met with controversy. For example, despite early indications of community acceptance of the scheme, a proposed potable recycled wastewater scheme for Toowoomba (a regional town in Queensland) was rejected at a referendum in 2006 (Water Futures Toowoomba, 2006). Other attempts to include potable recycled wastewater into new water infrastructure schemes have met similar 'eleventh hour changes of heart' (e.g., Gibson \& Apostolidis, 2001; Lamble, 1998; Roberts, 2008). Such resistance has occurred despite a view in scientific and, increasingly, political circles that harnessing wastewater streams is an essential infrastructural requirement of securing Australia's future water supplies (Bates \& Hughes, 2009; Gray \& Gardner, 2008; Water Corporation, 2009). Indeed, wastewater is increasingly being 're-framed' as an important resource and commodity (Gray \& Gardner, 2009). Concurrently, the significance of the social and political dimensions of these technological transitions is receiving increased attention (Broderick \& Gill, 2008).

The current prevailing approach to engaging communities in socio-technical transitions involves the adoption of various techniques designed to dampen ambivalence and gain consensus (e.g., Moss, 2009; Mouffe, 2005; Walker \& Shove, 2008). The dominant framework of communication taken by scientists 
is 'one-way', and has been identified as a path that is difficult and dangerous due to a narrow conceptualisation of 'the public' (Davies, 2008). For example, it is commonly assumed that infrastructure projects involving potable recycled wastewater fail due to a lack of capacity on the part of the broader community to comprehend detailed scientific information and risks (Gibson \& Apostilidis, 2001; Stenekes, Colebatch, Waite \& Ashbolt, 2006). An aversion to sewage, coined the 'yuck factor', has been invoked as the major psychological stumbling block in people's considerations (see Russell \& Lux, 2009 for an overview). The solutions to water crises are often framed in technological terms, with a history of engaging with the public at the level of informationprovision about technology as a means of garnering acceptance of a proposed scheme (Stenekes et al., 2006). The utilisation of a science-based risk assessment approach is often used in conjunction with an assumption that emotion, irrationality and opposition (particularly in regards to health risks) underlie existing community opinion and potential future opposition (Renn, 2004). As a result, agencies involved in water provision generally attempt to alleviate concern and bolster public support to technological water augmentation solutions by expressing its suitability in terms of probabilistic health risks. The path less travelled is one of participatory engagement with the community to identify and address broader areas of community concern about technological developments, despite evidence that such an approach is instrumental in successfully implementing potable reuse projects (Po et al., 2003). 


\section{The formulation of 'risk'}

Community and technical people think differently about emerging technologies and their associated risks (Gregory, Slovic \& Flynn, 1996; Slovic, 1987). Technical experts exhibit a predilection for probabilities of adverse health outcomes, but for the majority of people, risk perceptions are said to be more intuitive (Renn, 2004). Several studies have suggested that the lay community have trouble understanding probabilistic statements due to a host of attentional and cognitive biases (Jaeger, Renn, Rosa \& Webler, 2001; Johnson, Hershey, Meszaros \& Kunreuther, 1993; Renn, 2004). Indeed, these biases are so pervasive that technical and scientific experts are themselves not immune, leading to faulty calculations and inferences of probability in the first instance (Freudenburg, 1988; Johnson \& Covello, 1987; Lahsen, 2007).

Intuitive risks are based on how information regarding a technological solution is communicated, psychological mechanisms for dealing with uncertainty, and previous experience with and exposure to associated dangers (Renn, 2004). The way information is presented, or 'framed', can also influence the way people engage with a topic (Arvai, Gregory \& McDaniels, 2001; National Research Council, 1996; Slovic, 2000; Tversky \& Kahneman, 1981), as can associations transposed to new technologies and phenomena derived from other, more familiar, objects or categories (Fiske, 1982; Walker, Broderick \& Correia, 2007).

Factors beyond threats to one's health (and indeed beyond risk perceptions in general) also contribute to decision-making about technological solutions in 
the areas of genetically modified food (Yee et al., 2008), nuclear power (Peters \& Slovic, 1996), nanotechnology (Randandt \& Renn, 2008), DNA technology (Siegrist, 2002), and recycled wastewater schemes themselves (Frewer, 1999; Nancarrow, 2008). Ethical concerns, values, trust and distrust in regulators, information providers and scientific institutions, cultural considerations, and perceptions of social exclusion from the decision-making process may contribute to reactions, responses and resistance to new technologies (Bickerstaff, Simmons \& Pidgeon, 2008; Frewer, 1999; Nancarrow, Leviston, Po, Porter \& Tucker, 2008; Ross, 2005, Stenekes et al., 2006; Warner, 1999).

While communication plays the bridging role in community risk formulation for technologies, it is often the technical experts who find themselves as the mouthpiece, advocator and promoter for a particular solution. It is perhaps understandable that, when a scientific definition of what constitutes 'sufficient evidence' is met with scepticism in some quarters, the expert concludes that the community would be convinced 'if only they knew what I knew', and push the barrow of scientific enlightenment as the panacea for community uncertainty (e.g., Davies, 2008). 'Perceived risk', with its assumed accoutrements of irrationality and emotionality, is thus characterised as differing from 'real' or 'expert' assessments (Freudenburg, 1988; Russell \& Lux, 2009). To compound misunderstanding, the community is often treated as a 'space' between state and markets - an idealised and homogenous community that is removed from the expert and often viewed nostalgically by policy and scientific stakeholders (Rose, 1999; Schofield, 2002). By 
Domain-based perceptions of risk

consequence, communication of technologies becomes a blend of technocratic advocation, promotion and defence of demarcated scientific knowledge and boundaries (e.g., Gieryn, 1983).

As Davies (2008) identifies, little work has been conducted on the ideas and assumptions behind scientific assessments of public communication and engagement. This paper tests the idea that stratagems focussing on public acceptance of technological innovations to water security may simplify the complexity of the institutional issues surrounding water recycling by misappropriating the concerns of the community to the realm of emotionality, irrationality, and personal health risks.

The case study presented here illustrates how technical experts interpret community perceptions of risk, and identifies the extent to which community and technical experts differ in their risk perceptions towards a proposed potable recycled wastewater scheme. The study, conducted in Perth, Western Australia, concerns the augmentation of the drinking water supply through the injection of recycled wastewater into an underground aquifer (a process known as Managed Aquifer Recharge, or MAR). Issues of 'acceptance' and the structuring of community and technical perceptions of risks associated with the scheme are elicited using $Q$ Methodology. 


\section{Methodology}

\section{Research context}

In accounting for projected reduced rainfall coupled with a growing population, the Water Corporation of Western Australia (WCWA) has estimated that an additional 120 gigalitres of water per annum will be required by the year 2030 - more than $40 \%$ of current annual use (Water Corporation, 2009). MAR (also known as groundwater replenishment) is considered by the WCWA to have major potential in securing Perth drinking water supplies. It is also thought that MAR could assist in maintaining the environmental sustainability of the aquifer Perth relies on for approximately $60 \%$ of its drinking water supply (Water Corporation, 2009). The technical viability of using MAR in Perth is currently being explored and discussed within the scientific community. Trials involving MAR for both non-potable and potable uses are occurring increasingly in urban Perth and in nearby regional areas and are the focus of a major, multidisciplinary study being funded under the Western Australian Premier's Water Foundation. The research presented here forms one aspect of those investigations (for an overview of study findings see Bekele et al., 2008).

\section{Q-Methodology}

Q-Methodology has been used in disciplines ranging from social psychology and ecological economics through to cultural geography to analyse the structure of discourse (Addams \& Proops, 2000). It has been applied in the 
contexts of river and ocean management (Raadgever, Mostert \& van de Giesen, 2008; Tuler \& Webler, 2009), climate change (Niemeyer, Petts \& Hobson, 2005), and nuclear technologies (Venables, Pidgeon, Simmons, Henwood \& Parkhill, 2009), but has yet to be used to investigate recycled water in a research or policy setting.

Q-Methodology is a technique that captures similarities and differences between participants about a range of issues surrounding a particular topic (Previte, Pini \& Haslam-McKenzie, 2007). The issues, elicited through a series of focus groups, are captured in a diverse range of statements designed to reflect the broadest possible range of issues relating to a particular topic. Participants are asked to rank the statements on a continuum from 'most unlike' to 'most like' their point of view (McKeown \& Thomas, 1988; Previte et al., 2007; Simmons \& Walker, 1999).

The computational procedures for Q-Methodology factor analysis are similar to the ' $R$ ' factor analysis technique: that is, it is an analysis based on an assessment of relationships among variables. The sequential application of multiple regression and factor analysis allows identification of groups of people based on their opinion toward sets of statements (Barry \& Proops, 1999).

Rather than trying to understand the factors that influence people's acceptance of MAR in a way that generates the most common pattern across a range of people, an approach typical of survey methodology, Q- 
Methodology captures the way that these factors may be represented in the decision-making of individuals (Robbins \& Krueger, 2000). It is a nonreductive technique that opens up multiplicity, complexity, tension and inconsistency around a particular issue or topic (Previte et al., 2007). That is, Q-Methodology reflects the different way that these variables (e.g., perceptions of risk, trust or emotion) combine within individuals, which allows for different typologies of decision-making patterns to emerge. It is a useful methodology in this instance as it can reflect the highly complex context and the consequent highly complex structuring of opinions, judgements and understandings of MAR from a range of lay and expert perspectives (Robbins \& Krueger, 2000; Simmons \& Walker, 1999; Stainton-Rogers, 1998).

\section{Procedure}

A scoping phase was conducted firstly, to develop an understanding of the underlying themes and topic areas (termed the 'discourse') about the use of recycled wastewater for indirect potable use, and, secondly, to develop a set of interconnected claims and statements that reflect the breadth of the identified themes and topics (termed the 'concourse'). A combination of focus groups with community and technical experts, individual unstructured and semi-structured interviews, literature reviews, media and other sources of public comment revealed, in no particular order, the following themes: Unknown risks and uncertainties; system failure risk; relative and competitive risks; political risk; personal health risk; population health risk; intergenerational issues and risk; financial risk; environmental risk; 
Domain-based perceptions of risk

perceptions of scientific and community responses to risk; chemical/toxicological risk; voluntary versus imposed risk; tolerability and resignation to risk; emotion; trust; time wastewater had spent in aquifer; aesthetics and water quality; geographical location and fairness; fairness (general); alternative futures; perception of abundant supply; societal issues; and management (including scientific, policy and infrastructure management/knowledge).

The initial concourse contained 584 statements. This was decreased to 62 by eliminating repetitive or overlapping statements whilst retaining the widest possible number of themes for the final Q-Statement set.

Two samples of participants were recruited into the study - one of community members, and one of technical experts. Community participants were selected from a range of northern Perth suburbs whose drinking water is supplied by the aquifer that would be replenished by the recycled wastewater. A random selection of participants was invited to attend one of five community workshops. Technical participants were chosen who (i) attended the technical scoping focus groups, and (ii) did not attend the focus group when originally contacted but expressed a willingness to be involved in future stages of the research. The technical sample included participants from CSIRO, Water Corporation, University of Western Australia, Department of Water, Department of Health, and Department of Environment, and included a variety of scientific disciplines - including six from the social science disciplines. In all, 37 (19 male and 18 female) community participants and 20 technical 
experts (12 male and 8 female) completed the Q-sort from their own perspective. Fourteen of the technical participants went on to complete a Qsort with the instruction to sort as they thought a 'typical' community member would sort - the technical participants with a social science background were excluded from this exercise due to involvement in previous phases of the research and a subsequent heightened awareness of community attitudes and preferences. ${ }^{2}$

Participants were asked to read a short description of a scenario where MAR was used for potable wastewater reuse in Perth. Participants were then asked to read 62 cards, each card containing a different Q-Statement, and place them into three piles: one pile representing statements that were like their point of view, one pile containing statements that were unlike their point of view, and another pile containing statements that they felt uncertain about or neutral towards. Participants were then asked to place the cards on a Q-Sort board consisting of 62 card-spaces arranged in 11 columns in a normal distribution; with three spaces on the two outside columns representing 'most like my point of view' and 'most unlike my point of view' respectively, four spaces in the next outermost columns, five spaces in the columns inside those, six inside those, eight inside those, and 10 spaces in the innermost column. Participants were asked to place each card onto one of the 62 card-

\footnotetext{
${ }^{2}$ Q-Method is used with smaller sample sizes as the method is not concerned with generalisability of results. Sample size is often between 30-40 sorters (Addams, 2000). In fact Previte et al. (2007, p.139) have suggested that "a larger number of participants can be problematic, because they negate the complexities and fine distinctions which are essential features of qualitative techniques". While the technical experts sample in this instance was smaller than the community sample, it represented a sizeable proportion of key decision-makers tasked with investigating the feasibility of such a scenario at the time of testing.
} 
Domain-based perceptions of risk

spaces on the Q-Sort board, alternating between two of their three preestablished piles: the pile with statements most like their point of view and the pile with statements most unlike their point of view, until they ran out of cards. They were then instructed to move onto their remaining pile of cards - those with statements that they were uncertain about, and place these in the remaining card-spaces. ${ }^{3}$

Participants were asked to record details of how they made their decisions, any statements that they had problems with, and any other comments (e.g., new statements that would more effectively capture their point of view) on a feedback form. These feedback forms were used to assist the brief interviewing process at the end of each Q-Sort scenario. In addition to the QSort, participants completed a brief questionnaire asking them whether they would drink water provided through the MAR scheme.

PQ Method software (a freeware package available on the internet, available at http://www.Irz-muenchen.de/ schmolck/qmethod/, accessed 09/10/09) was used for the analysis of the results (Previte et al., 2007; Schmolck, 2002). Factor analyses of the Q-Sort data allowed the identification of patterns across individuals. Each emerging factor consisted of individuals who had similarly sorted the statement items, and hence were considered as holding a generally similar decision-making framework (Previte et al., 2007). It should

\footnotetext{
${ }^{3}$ Most Q-Methodology studies use this forced normal distribution approach, although some give people the top line only and allow participants to sort as many statements in each column as they desire (Eden, Donaldson \& Walker, 2005). A forced normal distribution does not impact dramatically on the results of the research when contrasted with a free distribution (Niemeyer, Petts \& Hobson, 2005). A forced normal distribution was chosen for this study to encourage participants to think carefully about the relative ranking of statements (Niemeyer, Petts \& Hobson, 2005).
} 
be noted that all statements could be of importance to a person but, as individuals were directed to differentiate between the statements, statement placements represented relative rather than absolute positions. For this study a 'Principle Components Analysis' with 'Varimax Rotation' was chosen. It is recommended that researchers run from a seven-factor to two-factor solution before accepting a final solution (Previte et al., 2007), as conducted in this study.

\section{Results}

\section{Community Perspective}

Five factors were found to be the best solution for the Q-sorts of the 37 community members. They represented the simplest structure that gave a clear conceptual distinction between factors whilst accounting for the most variance. The factor extraction and exclusion were in line with the rationale suggested by Addams (2000) and Swedeen (2006). The first five factors explained $57 \%$ of variance after rotation and had multiple cases loading on each factor. The five factors accounted for 32 of the 37 participants. The remaining five participants did not load significantly onto any factors.

Table 1 shows the factor scores for each statement. The factor score for each statement is a weighted score of the rank orderings given to that statement by all Q-sorts associated with the factor. It therefore represents the 
Domain-based perceptions of risk

general consensus viewpoints of the participants who ascribe strongly to the view expressed in that statement.

Insert Table 1 about here.

Community Factor 1: Confident, Accepting, Governance-Focussed, Appeased Health Concerns

Statements that are important to this factor are $7,9,13,14,15,16,34,35,60$ (agreement) and 20, 24, 26, 45, 59 (disagreement). This factor is characterised by relatively high levels of acceptance, a focus on responsible management and a marked lack of health concern. Fourteen of the 17 participants loading on this factor answered 'yes' when asked if they would drink water provided through this scheme, with two unsure and one answering no. The factor explained $23 \%$ of the variance.

More specifically, people in this factor can be characterised in the following way. Generally, they do not have a problem with MAR, supported by the view that sufficient knowledge of water testing, disease minimisation and harm reduction exists for the scheme's viability. They cite that other countries have been drinking recycled water for years with no adverse effects. Health is important to them, but they feel that the health risks associated with this scheme have been overcome; hence there is little concern with potential adverse health effects of drinking recycled water, little worry about the effects 
of 'gender bending' chemicals, and little concern with the effect of the water on unborn babies. The notion of an emotive disgust impediment to drinking recycled wastewater is dismissed, with strong disagreement to the statement - "the thought of drinking sewage disgusts me".

Despite their positive views of the MAR scheme, people loading on this factor have strong views about how the scheme needs to be managed. They agree that there needs to be strong legal processes in place to oversee such a scheme, and that government bodies would be more accountable than privatised companies. They also strongly believe that reducing industrial emissions to the wastewater stream should be a priority.

There is an attitude that water is not currently being managed in a sustainable way and that, as we are already drawing water from the aquifer, we should be replenishing it. There is also a moderately strong view that if the water is clean enough to drink, it will be clean enough for the environment, and that once the wastewater has been in the aquifer for a number of years it becomes similar to groundwater.

\section{Community Factor 2: Sceptical, Not Accepting, Unknown Risk,} Alternative Option, Inclusion of Community

Statements that are important to this factor are $2,21,22,23,32,53,54,61$, 62 (agreement) and 5, 13, 16, 39, 42, 48, 49 (disagreement). This factor is characterised by a rejection of the scheme, scepticism of the current scientific 
knowledge available, and a focus on alternative water augmentation options. Five of the seven participants loading on this factor said that would not drink the water provided from the scheme, with two indicating they were unsure. Factor 2 explained $13 \%$ of the variance.

Participants loading on this factor express strong negative views about MAR. They do not have faith in the filtration process, and are unsettled by what could go wrong with the scheme. They feel that there is not yet adequate information and knowledge about water testing. They do not feel they can trust the media to provide them with accurate information.

Despite their misgivings about the scheme, people loading on this factor are not overly focused on possible adverse health effects from the MAR scheme. There is, however, a strong belief that there are better sources and options for water augmentation and that there needs to be a focus on behaviour change and reducing water use in the first place. Likewise, they believe strongly that government should be looking at water augmentation options that are the safest, not the cheapest, and that we could forgo the option of using recycled wastewater as an indirect potable water source.

There is a strong view that MAR needs the approval of the entire community, even if that takes some time, and that it is a fundamental public issue that needs more community debate before a decision is made. There is rejection of the notion that their lives are too busy to tolerate the scheme even if they 
did not like it, or that it can be accepted at face value that it is safe and so consume water from it on that basis.

\section{Community Factor 3: Pessimistic, Ambivalence, Accepting but suspicious, Concerned with the environment}

Statements that are important to this factor are 1, 11, 14, 20, 22, 40, 50 (agreement) and 5, 7, 9, 59, 54, 62 (disagreement). Two of the three participants loading on this factor indicated that they would drink recycled wastewater, with the other indicating that they were unsure. This factor explained $7 \%$ of the variance and is primarily defined by its negativity. There is little agreement with any of the statements, except for those that capture negative issues and concepts.

Participants loading on this factor express strong views that the community does not have the required expertise or information to make a decision about MAR. They are worried about water-borne diseases that are not yet known about, and are concerned about the health effects of drinking the water, including the build-up of chemicals and toxins in the body. They feel strongly that MAR could contaminate the aquifer and do not consider that the wastewater would become indistinguishable from existing aquifer water over time. Despite their concerns, participants loading on this factor would drink recycled water rather than live with the anxiety that they could run out of water to drink; they disagree strongly that there are other alternatives for drinking water in WA other than MAR, nor do they think that WA is managing its water 
well enough to not need wastewater recycling. They disagree strongly with the notion that, being a rich and developed nation, we can avoid drinking recycled sewage.

Management of the MAR scheme is important to these participants. They disagree that government bodies would be more accountable than private companies, or that the media can be trusted for MAR information. They strongly believe that a management priority should be to reduce industrial emissions entering the wastewater stream.

\section{Community Factor 4: Ambivalence, Not Accepting and Suspicious,}

\section{System Risk Focussed}

Statements that are important to this factor are $11,12,15,24,37,41$ (agreement) and 1, 16, 25 (disagreement). This factor is characterised by mixed feelings towards the MAR scheme. One of the participants who loaded on this factor said that they would not drink recycled wastewater, with the other participant indicating that they were unsure. This factor explained $7 \%$ of the variance.

Participants in this factor strongly reject the view that they do not have problems with MAR. They would rather live with the anxiety of running out of water than drink recycled water. Despite this rejection of the scheme, participants also indicate strong affinity with the statement "I support it, but you will have a hard time convincing others". 
Potential system failure is an important consideration for participants in this factor. They express strong agreement with the possibility of aquifer contamination. They also express strong concerns about the risk of breakdown. They emphasise that the scheme needs to be run in accordance with strict legislative and legal requirements. The potential effect of 'genderbending' chemicals is of particular concern. By contrast, potential future health effects of the scheme on future generations and any unknown waterborne diseases are not an issue.

\section{Community Factor 5: Trusting, Acceptance, Faith in Technology}

Statements that are important to this factor are $6,13,16,30,35,42,45$ (agreement) and 10, 11, 18, 28, 37 (disagreement). This factor is characterised by strong acceptance of the scheme, trust in the science behind it and a downplaying of perceived risks. Two of the three participants who loaded on this factor said that they would drink the water from the scheme, with the other indicating that they would not. This factor explained $7 \%$ of the variance.

Based on a trust in the science, the knowledge, the process and the technology, participants loading on this factor express no problem with the MAR scheme. There is a belief that if the water is clean enough to drink it will be clean enough for the environment. Following from this is the opinion that you can overcome any risk if you spend enough money on it. 
Participants belonging to this factor typically view themselves as 'rational thinkers', and strongly object to the stereotypes of members of the community as emotional and lacking in knowledge. This is expressed through a strong disagreement to the view that people do not really know what comes out of their taps now, and with the idea that scientists base their decisions on facts, and the community on feelings. Conversely, there is a high agreement rating with the statement regarding feeling disgust at the thought of drinking sewage. This may be because those who are generally accepting of the scheme hold a strong belief that the technological process separates the derived product from its source, in effect making MAR water fundamentally different from sewage. ${ }^{4}$

\section{Consensus statements}

There were three 'consensus statements' among the factors (statements where ratings did not differ significantly from factor to factor). All three statements $(19,31$ and 36$)$ were rated relatively neutrally. The areas of consensus (or, in this case, agreed neutrality) are the suggestion that political interests or processes could compromise the scheme, that we run the risk of paying too much to get the water at a standard the community will accept, and a concern that the MAR process will be too energy intensive.

\footnotetext{
${ }^{4}$ This is supported by post-sort interviews for this group. Interestingly, this is in contrast to a number of people who we interviewed in the scoping phase who strongly emphasised the lack of separation between sewage and the derived MAR water.
} 


\section{Technical Perspective}

Four significant factors emerged for the twenty technical experts who undertook Q-sorts for their own perspective. These factors accounted for $65 \%$ of the variance. All factors were conceptually different and had at least one person loading on them. The four factors accounted for 18 of the 20 technical expert participants. The remaining two participants did not load significantly onto any factors. Table 2 displays the factor scores for each statement.

Insert Table 2 about here.

Technical Factor 1: Confident, Accepting, Trusting of Science and Process, Strongly Not Health Focused, Perceived Community/Technical Divide

Statements that are important to this factor are 4, 6, 8, 9, 13, 15, 16, 30, 34, 37, 54 (agreement) and 1, 2, 5, 21, 22, 27, 29, 45, 57, 58 (disagreement). Ten of the 20 technical expert participants loaded on this factor, eight of whom stated that they would drink water from the scheme, with two stating that they were unsure. This factor accounted for $27 \%$ of the variance.

Participants in this factor can be characterised as having a high level of support for the MAR scheme. They prefer this option of using recycled wastewater over a scheme where the water is stored separately from other 
drinking water supplies. Their acceptance is also reflected in the high level of disagreement with the statement relating to disgust in drinking recycled water. They strongly believe that MAR will not influence the aesthetics of the water and that, once the wastewater has been in the aquifer for a number of years, it will become indistinguishable from existing groundwater.

Participants loading on this factor also express disagreement with the possibility of adverse health outcomes. They show relatively high levels of trust in authorities, science, and current knowledge, and would be reassured by a system with an independent body. They strongly believe that strict legal and legislative requirements are needed to make sure the scheme is well managed. They believe any problem associated with the scheme can be overcome by investing money. They do not trust the media to provide them with information about MAR.

There is a focus on the 'governance' issues of water in Western Australia, with the strong belief that water is too cheap and should cost more. They strongly disagree that recycling wastewater will encourage people to use more water, and similar disagreement that Western Australia is managing its water well enough not to need recycled wastewater. There is a belief that scientists base decisions on fact and communities base their decisions on feeling. 
Technical Factor 2: Sceptical, Lack of Trust/Faith/Confidence in Science, Process and Technology, Strongly Health Concerned, Community

\section{Focused}

Statements that are important to this factor are $2,3,10,11,12,19,20,21,25$, 43 (agreement) and 4, 5, 6, 8, 30, 37, 39, 41, 45, 59 (disagreement). Five participants loaded on this factor, with one saying they would drink the water, two saying 'no', and two being unsure. The factor accounted for $18 \%$ of the variance.

Participants loading on this factor can be characterised as lacking trust in science and authorities. They doubt the accuracy of scientific processes and the extent to which scientists know how different chemicals involved in MAR might react together. They would not be reassured if an independent panel of experts presided over scheme safety aspects. They also believe strongly that political interests could compromise the scheme. There is marked concern about the uncertainty of what could go wrong with the scheme. One of their biggest concerns is health effects, including the outbreak of diseases and how the scheme might affect generations to come. They do not have faith in filtration and do not believe any problem can be overcome by putting enough money into MAR.

These participants also have strong opinions regarding the 'community', believing that MAR is a fundamental public issue that needs more community debate. They disagree that the community does not have the required 
information or expertise to make decisions, and disagree that the community bases its decision on feeling and that scientists base their decisions on facts. There is also strong disagreement with the viewpoint that people can just switch to bottled water if people are not happy with the scheme.

\section{Technical Factor 3: Defiant, Strongly Not Health Focused, Environmentally Concerned, Lack of Trust/Faith}

Though only one person loaded on this factor, upon observation of the pattern of responses it was decided that differences between this and other factors were significant, and of interest at a theoretical level. Statements that are important to this factor included 11, 14, 29, 31, 33, 36 (agreement) and 4, 6, $8,18,19,23,24,25,26,37$ (disagreement). This participant said that they would drink the water from the scheme.

The participant loading on this factor can be characterised as having low levels of trust in authorities and scientists. They strongly believe that political interests could compromise the MAR scheme. They do not agree that the presence of an independent body of experts would be reassuring, nor do they think that people are unaware of what comes out of their tap now. They express disagreement with the sentiment that scientists base their decisionmaking on fact, while communities base it on feeling.

People on this factor are not concerned with 'gender bending' chemicals and the possible effects on reproductive health, unborn babies, young children or 
generations to come. They are, however, concerned that the MAR process would be too energy intensive. Despite concerns, they feel that they can tolerate drinking recycled water. They agree strongly that if they are told it is safe to drink, they will probably get used to drinking the water. They believe that those who pollute or use the most water should be made to use recycled water before anyone else.

Technical Factor 4: Doubtful, Environment Focused, Mildly Health

Concerned, Lack of Faith/Trust/Confidence in Science, Process and Technology

Statements that are important to this factor included 4, 7, 11, 12, 14,15, 23 , 33, 34, 39, 43 (agreement) and 5, 6, 13, 25, 30, 35, 36, 41, 55, 57, 58 (disagreement). Two participants loaded on this factor, with one participant saying they would drink the water, the other saying they would not. This factor explained $10 \%$ of the variance.

This perspective is characterised by quite a strong environmental focus, with consideration given to the risks of contamination and environmental impact on the aquifer, and the view that we should be replacing the aquifer water we use. They disagree with the notion that if the water is clean enough for humans it would be clean enough for the environment. This environmental consideration appears to be confined to the aquifer environment; they are not overly concerned about the energy intensity of the MAR process. 
Participants loading on this factor appear to have relatively little confidence in the scientific, management and technological systems surrounding MAR. This is captured in concerns about breakdowns, lack of faith in scientific knowledge and processes, and a lack of faith in filtration. There is a very low level of trust in the media as a source of information. By contrast, they would be reassured if there were a panel of independent experts, and they consider government bodies more accountable than private companies. There is a strong opinion regarding the need for legal and legislative requirements, and the need to reduce industrial emissions. They disagree that money is the answer to overcoming problems to do with MAR.

This perspective does not think that Western Australia is managing its water well enough. They do not consider population growth to be the real issue, nor do they consider that using recycled water would encourage greater water use. There is a belief that the community do not have the required expertise or information to make an informed decision anyway.

\section{Consensus statements}

Most of the statements that achieved 'consensus' among the four factors that emerged from the technical perspective $(28,32,38,51,52,54$, and 61$)$ fell in the neutral range. One statement (5) was rated negatively for all factors: trust in the media for information. 


\section{Technical Perceptions of Community}

Two factors emerged from the Q-sort of 14 technical people regarding their perception of community attitudes towards drinking recycled wastewater. As previously stated, technical participants from the social science disciplines were excluded from this Q-sort. The factors accounted for $64 \%$ of the variance. Both factors were conceptually different and had at least one person loading on them. Table 1 displays the factor scores for each statement.

\section{Technical Perceptions of Community Factor 1: Challenging, Not}

\section{Accepting, Health Focused, Lacking Trust and Confidence}

Important statements to this factor included 1, 2, 10, 15, 20, 21, 22, 23, 24, 25, 26, 45 (agreement) and 5, 6, 16, 17, 30, 39, 42, 46, 48, 55 (disagreement). Eleven participants loaded on this factor, which explained $45 \%$ of the variance.

Technical participants who loaded on this factor can be characterised as thinking that the community will strongly reject MAR scheme, and that the community will be relatively disgusted by the thought of drinking the water. They also strongly believe that the community will not find the risks of MAR small in comparison to other risks. There is a moderately strong perception that the community would require strict legislative requirements. 
Domain-based perceptions of risk

Technical participants loading on this factor strongly believe that the community will have significant concerns about the health impacts of the scheme, including the outbreak of diseases and the chemical build-up of toxins. Further, that the community lacks trust in science, has little or no faith in filtration and is very concerned with the uncertainties of the scheme, including the possibility of human and mechanical errors. They think the community would strongly disagree that putting enough money into MAR would overcome any risks associated with the scheme.

There is a perception that the community will strongly disagree to the suggestion of buying bottled water if they were not happy with drinking the recycled water. Participants on this factor think the community will not get used to drinking the water even if told it was safe. There is also a perception that the community disagrees that water is too cheap.

\section{Technical Perceptions of Community Factor 2: Resistant, Health}

Focused, Reassured by Science and Government/Independent Process, Focused on Societal Issues

Important statements to this factor included 4, 6, 7, 15, 20, 23, 24, 25, 26, 28, 45,55 (agreement) and 27, 30, 31, 36, 38, 48, 50, 51, 56, 58, 59, 61 (disagreement). The second factor, explaining $19 \%$ of the variance, had three people loading on it, with one participant loading on it 'negatively' (indicating that this person held diametrically opposed views to the other participants loading on this factor). 
Similar to Factor 1, technical participants in this factor felt that the community would be very concerned with the health effects of the MAR scheme. Unlike Factor 1, technical participants who loaded on this factor perceived the community to have high levels of trust in science and government bodies. There was also a stronger perception that legal and legislative requirements would be important for the community, and that a panel of independent experts would reassure them.

Despite the high level of trust captured from participants, there is also a perception that the community would not just get used to drinking it if they were told it was safe, and rejection of the idea that they would be more happy to drink recycled water than live with the anxiety that we may run out of water to drink. The participants who loaded on this factor thought the community would not agree with the notion that, as scientists cannot agree on many things, the community should not be expected to.

The factor is also characterised by the following perceptions of community: recycling wastewater will increase household water use, not believing that the controversy of MAR is due to the fact it is a new issue, a belief that water is too cheap and should cost more, a lack of support for the real issue being population growth, a lack of support that Western Australia is managing its water well enough to negate the need for recycling, and the dismissal of the idea that, as a developed country, 
we have the technology and finances to not have recycled water. There is also the perception that the community is unconcerned with MAR being too energy intensive.

There is also an emphasis on the financial aspects of risk, with the perception that the community would not accept that sufficient financial investment would overcome any risk. Conversely, there was a perception that the community would disagree that we risk paying too much to get the water treated to a level that the community is happy with. Also, there is the perception that the community would be unhappy if there was uneven distribution of the MAR water whereby some people would have to drink it while others did not. This factor perceived that the community would not be concerned about the smell or taste of the MAR water, yet thought that the thought of drinking sewerage disgusts the community.

\section{Consensus statements}

Half of the statements $(n=31)$ in the $Q$-Sample for this scenario were consensus statements. Many of the strong 'positive' statements that gained consensus were the health risk related statements $(20,23,24,25,26,28)$. The strongly 'negative' consensus statement was that risks could be overcome with enough financial investment (30). Mildly negative statements concerned tolerability and resignation to risk $(48,50)$, emotion (45), problems with filtration (42), relative risk (18), and trust of the media (5). Statements considered neutral by consensus included systems failure $(11,12)$ and 
management issues $(13,14)$, the compromising potential of political interests (19), fairness issues $(28,29)$, safety over financial considerations (32), perceptions of community response $(37,40,41)$, chemical and toxicological risk $(43,44)$, voluntary versus imposed risk (47) and alternative futures and perceptions of abundant supply $(53,54,56,58)$.

Factors that emerged from the Q-sorts reported above are summarised in Table 3.

Insert Table 3 about here.

\section{Discussion}

This case study sought to investigate the way in which technical experts interpret community perceptions of risk, and to identify the extent to which community and technical experts differ in their risk perceptions towards proposed potable recycled wastewater schemes. Specifically, it sought to test the assumption that community decision-making is based primarily on emotion and personal health concerns.

Despite a 'general consensus' in the literature about the salience of emotionbased assessments for community in making decisions about risk, particularly where wastewater is concerned, the emotion statement - The thought of 
drinking sewage disgusts me - failed to play a significant role in all but the last of the community factors. This suggests that the link between emotion and risk is complex, and that emotion-based assessments go beyond the 'yuck factor' to include other more contextual considerations and assessments, including governance accountability and regulatory concerns, holistic water supply management, and a desire for participatory decision-making. While the self-selected nature of the community sample means those with strong preexisting attitudes towards MAR are over-represented, the emerging community factors allow us to conclude that there is significant variety in decision-making frameworks within the community. By contrast, only two factors emerged in the technical perceptions of community decision-making.

Consensus statements on technical perceptions of community risk assessments revealed themes that unified both factors. These statements included perceiving the community as health concerned, as having a belief that financial investment would not necessarily overcome risk, would not tolerate or be resigned to risk, is emotion-focused, would perceive problems with information from the media, and would disagree about the risks of MAR being low compared with other risks. As a whole, technical experts thought communities would be relatively unconcerned (compared to other issues) about systems failure, management, political compromise, fairness, financial risk, chemical and toxicological risk, voluntary versus imposed risk, alternative water augmentation options and perceptions of abundant supply. Conversely, the only statements that achieved consensus among community participants in this study concerned political compromise, the risk of paying too much to 
get the water to a level the community would accept, and the energy intensiveness of MAR. All of these statements were ranked relatively neutrally. So, while there were many statements that unified technical perceptions of community assessments of risk, this perception did not accurately reflect the complexity and lack of consensus among the community when it came to thinking about risks associated with MAR for indirect potable reuse.

The dominant depiction made by technical experts of community members suggests that community risk perception is inaccurately caricatured as relatively non-accepting, emotion-focused and driven, focused on health concerns, and with a lack of trust and confidence in scientific, policy and management processes. Both factors that emerged for perceptions of community strongly highlighted the health focus of the community. The strongest health concern that actually emerged from community members was for the factor that expressed ambivalence towards MAR (Community Factor 3).

Also instructional was the technical participants' response to the direction to "sort as you think a typical member of the community would". We noted (though cannot document) that there was ready acceptance of this verbal instruction; indeed many displayed an extra element of surety not evident when conducting sorts from their own perspective, a perception backed up by comments during post-sort interviews. While we do not suggest that our 
technical experts were incapable of recognising the variation of perspectives that may exist within the community, the sorts do suggest that there is a particular characterisation of community that is 'most salient' to technical experts. If scientific and technical experts do indeed view themselves as distinct from the community, the sorts are consistent with literature suggesting a tendency for people to perceive homogeneity in 'outgroups' relative to their own variability (Mullen \& Hu, 1989). The inaccuracies of the technical expert rendering of community decision-making is also in keeping with attribution theory's fundamental attribution error - the tendency to attribute other groups' or people's decision-making to personal attributes such as attitudes and values, rather than to situational factors (Ross, 1977). By contrast, the individual or group deems decision rules as guiding their own decision-making (Allison \& Messick, 1985).

The need for transparent political, legal and scientific processes was important for nearly every community factor that emerged, regardless of the level of support for the proposed MAR scheme. Regulations and responsibility for the day to day management of the scheme were highlighted, with a large majority supporting a government run-and-owned system - consistent with previous research showing hesitancy and scepticism towards privately run schemes (e.g., Leviston et al., 2006). Such concerns have been demonstrated to link inextricably with trust in the organisations charged with running and regulating augmentation schemes, especially ones involving perceived risks to human health (Alexander et al., 2008; Sztompka, 1999). Beck (1992) argues that one of the consequences of modernity is ever- 
increasing technological complexity reliant on expert systems. Giddens (1991) argues that this 'mediated' risk is a major source of contemporary anxiety, and adds that when trust in the institutions charged with mediating this risk is lost, the individual is plunged into uncertainty and anxiety. Beck argues that modern society has become accustomed to expressing this anxiety in terms of risk. Communicating the 'fail-safes' of a system - immunity from human error and the innocuous consequences of system breakdown (so long as that information is true) is the assurance that much of the community may seek before committing to the scheme without major reservation.

As evidenced by the emergent factors for community members, the strongest typology consisted of people who were supportive and accepting of the scheme. The features of the strongest typology for technical perceptions of community decision-making insinuated entrenched opposition (more hopefully, the characteristics of the second factor for technical perceptions of community - on which two of our technical experts loaded positively possessed a greater degree of correspondence with the strongest community factor). ${ }^{5}$ Assuming a 'default' position of opposition and neglecting widespread support that may actually exist for a proposed scheme risks orienting the discourse as a 'debate' to be 'won' or 'lost', in so doing reinforcing perceived battle-lines between reified knowledge and folk wisdom. A comparison of the most dominant factors for the community and for the technical experts' own

\footnotetext{
${ }^{5}$ While the second technical expert factor exhibited a preference for community involvement and some disagreement with emotion-driven characterisations, this factor was populated mostly with participants from a social science background
} 
Domain-based perceptions of risk

perspectives reveals how similar the decision-making frameworks of these two 'groups' actually are.

\section{Conclusion}

While it would be disingenuous to suggest that science-based risk assessment has no place in policy formulation, merely 'communicating' the rationales of scientific and technological expertise and decision-making in an attempt to solve the current water security issues in Australia, risks problematizing the political aspects of the scheme and undermining the political process as a legitimate community decision-making and consensusbuilding tool.

While the methodology used in this case study prevents the community decision-frameworks identified here being extrapolated to an entire community, it effectively demonstrates the complexity and heterogeneity of frameworks that exist within even a small sample of people. The results suggest that there is a systematic structure or orderliness to community views, though, despite the complexity and heterogeneity. A further limitation with a case study such as this is that it merely provides a 'snap shot' of decision-making frameworks, and cannot account for changes in risk formulation as the discourse of a debate takes on new proportions, characteristics or 'frames'. Of value would be research investigating whether individuals or factors change after intervention, either through the provision of information, after the characteristics of a discourse perceptibly shift, or after 
meaningful engagement between the community and technical experts or policy-making authorities takes place. Similarly, psychometric testing of emotion as a latent construct should be undertaken to provide corroborating evidence of the relative lack of importance of emotion in people's decisionframeworks.

The notable omission of a 'yuck factor' as a prominent concern for community demonstrates the limitations of ascribing motivations and drivers rather than identifying contextual issues of concern that could be generated in the process of deliberative discussions. Focusing exclusively on emotive aspects of community decision-making underestimates the complexity of community opinion, and effectively undermines planners' and researchers' ability to respond to actual community concerns, uncertainties and debates. Long considered the staple cause of rejection of schemes involving wastewater, the community appears as a whole to have moved beyond a 'toilet to tap' mentality to a more holistic conceptualisation of the issue. Scientific and decision-making communities should be open and responsive to new and increasingly multifaceted concerns that comprise the new arena of concerns. An assumption that members of the lay community and technical experts are in entrenched opposition ignores the existence of substantial proportions of the community who may think similarly to experts (and vice-versa!) and means that the diversity of accepting, uncertain, ambivalent or rejecting opinions may not be captured. A process is needed that recognises and respects the multidimensionality of risk assessments and risk perceptions, so 
that risk policy that adequately reflects and accounts for the multiple concerns of the broader community can be formulated.

\section{Acknowledgements}

This research was supported by the Premier's Water Foundation, an initiative of the Western Australian Government's State Water Strategy. The authors would like to thank the members of the Western Australian community for contributing their time to this research project, as well as the technical experts and their respective agencies for being willing and generous participants in out project. The authors would also like to acknowledge the following CSIRO project staff for assisting with the development of the research design and methodology: Blair Nancarrow, David Tucker, Natasha Porter and Sarah Nicol. The authors would like to thank lain Walker and Emma Yuen for reviewing this paper. 


\section{Reference List}

Addams, H. (2000). Q methodology. In H. Addams \& J. Proops (Eds.), Social discourse and environmental policy: An application of Q-methodology (pp. 14-40). Cheltenham: Edward Elgar.

Addams, H., \& Proops, J. (2000). Social discourse and environmental policy: An application of $Q$ methodology. Cheltenham: Edward Elgar.

Alexander, K. S., Price, J. C., Browne A. L., Leviston, Z., Bishop, B. J., \& Nancarrow, B. E. (2008). Community perceptions of risk, trust and fairness in relation to the indirect potable use of purified recycled water in South East Queensland: A scoping report. Urban Water Security Research Alliance Technical Report No. 2.

Allison, S. T., \& Messick, D. M. (1985). The group attribution error. Journal of Experimental Social Psychology, 21, 563-579. doi: 10.1016/0022$\underline{1031(85) 90025-3}$

Arvai, J. L., Gregory, R., \& McDaniels, T. L. (2001). Testing a structured decision approach: Value-focused thinking for deliberative risk communication. Risk Analysis, 21, 1065-1076. doi: 10.1111/02724332.216175 
Barry, J., \& Proops, J. (1999). Seeking sustainability discourses with QMethodology. Ecological Economics, 28, 337-345. doi:10.1016/S0921$\underline{8009(98) 00053-6}$

Bates, B., \& Hughes, G. (2009). Adaptation measures for metropolitan water supply for Perth, Western Australia. In F. Ludwig, P. Kabat, H. van Schaik and M. van der Valk (Eds.), Climate change adaptation in the water sector. London: Earthscan.

Beck, U. (1992). Risk society: Towards a new modernity. London: Sage.

Bekele, E., Toze, S., Higginson, S., Patterson, B., Blair, P., \& Heitz, A. (2008). Determining requirements for managed aquifer recharge in Western Australia: Progress report. CSIRO: Water for a Healthy Country Flagship.

Bickerstaff, K., Simmons, P., \& Pidgeon, N. (2008). Constructing responsibilities for risk: Negotiating citizen-state relationships. Environment and Planning A, 40, 1312-1330. doi:10.1068/a39150

Broderick, K., \& Gill, N. (2008). Guest editors' introduction: Water crisis? Socio-cultural and environmental dimensions of water and rivers. Geographical Research, 46, 255-257. doi: 10.1111/j.1745$5871.2008 .00521 . x$ 
Domain-based perceptions of risk

CSIRO (2007). Climate change in Australia: Technical report 2007. Canberra: CSIRO and the Bureau of Meteorology. Retrieved $2^{\text {nd }}$ June 2009 from http://www.climatechangeinaustralia.gov.au/technical report.php.

Davies, S.R. (2008). Constructing communication: Talking to scientists about talking to the public. Science Communication, 29, 413-434. doi: $10.1177 / 1075547008316222$

Eden, S., Donaldson, A., \& Walker, G. (2005). Structuring subjectivities? Using Q methodology in human geography. Area, 37, 413-422. doi: 10.1111/j.1475-4762.2005.00641.x

Fiske, S. T. (1982). Schema-triggered affect: Applications to social perception. In M. S. Clark and S. T. Fiske (Eds.), Affect and cognition: The $17^{\text {th }}$ annual Carnegie symposium on cognition (pp. 56-78). Hillside, NJ: Erlbaum.

Freudenburg, W. R. (1988). Perceived risk, real risk: Social science and the art of probabilistic risk assessment. Science, 4875(242), 44-49. doi: 10.1126/science.3175635

Frewer, L. (1999). Risk perception, social trust, and public participation in strategic decision making: Implications for emerging technologies. Ambio, 28, 569-574. 
Gibson, H. E., \& Apostolidis, N. (2001). Demonstration, the solution to successful community acceptance of water recycling. Water Science \& Technology, 43(10), 259-266.

Giddens, A. (1991). Modernity and self-identity: Self and society in the late modern age. Cambridge: Polity.

Gieryn, T.F. (1983). Boundary-work and the demarcation of science from nonscience: Strains and interests in professional ideologies of scientists. American Sociological Review, 48, 781-795. doi:10.2307/2095325

Gray, J., \& Gardner, A. (2008). Exploiting the unspeakable: Third-party access to sewage and public-sector sewerage infrastructure. In P. Troy (Ed.), Troubled waters: Confronting the water crisis in Australia's cities. (pp. 115-156). Canberra: ANU E Press.

Gregory, R., Slovic, P., \& Flynn, J. (1996). Risk perceptions, stigma, and health policy. Health \& Place, 2, 213-220. doi:10.1016/1353$\underline{8292(96) 00019-6}$

Hurlimann, A. (2007). Time for a water re-'vision'. Australasian Journal of Environmental Management, 14, 14-21.

Jaeger, C. C., Renn, O., Rosa, E. A., \& Webler, T. (2001). Risk, uncertainty, and rational action. London: Earthscan. 
Jeffrey, P., \& Jefferson, B. (2003). Public receptivity regarding in-house water recycling: Results from a UK survey. Water Science \& Technology, 3, 109-116.

Johnson, B. B., \& Covello, V. T. (1987). Summary. In B. B. Johnson and V. T. Covello (Eds.), The social and cultural construction of risk: Essays on risk selection and perception. Dordrecht: Reidel.

Johnson, E. J., Hershey, J., Meszaros, J., \& Kunreuther, H. (1993). Framing, probability distortions, and insurance decisions. Journal of Risk and Uncertainty, 7, 35-51. doi:10.1007/BF01065313

Johnson, T. A. (2009). Ground water recharge using recycled municipal waste water in Los Angeles County and the California department of public health's draft regulations on aquifer retention time. Ground Water, 47, 496-499. doi: 10.1111/j.1745-6584.2009.00587_3.x

Lahsen, M. (2007). Experiences of modernity in the greenhouse: A cultural analysis of a physicist "trio" supporting the backlash against global warming. Global Environmental Change, 18, 204-219.

doi:10.1016/i.gloenvcha.2007.10.001 
Lamble, S. (1998, January 18). Men's worst fear on tap. The Sunday Mail, retrieved August 24, 2009, from http://www.rag.org.au/sewage/sm18jan98.htm.

Landers, J. (2008). Singapore plans two more reuse plants, increasing its reliance on reclaimed water. Civil Engineering, 78, 33-35.

Leviston, Z., Nancarrow, B. E., Tucker, D. I., \& Porter, N. B. (2006). Predicting community behaviour: Indirect potable reuse of wastewater through managed aquifer recharge. Perth: CSIRO Land and Water.

Marks, J. S., Martin, B., \& Zadoroznyj, M. (2008). How Australians order acceptance of recycled water: National baseline data. Journal of Sociology, 44, 83-99. doi:10.1177/1440783307085844

Marks, J. S., Martin, B., \& Zadoroznyj, M. (2006). Acceptance of water recycling in Australia: National baseline data. Water Journal of the Australian Water Association, 33, 151-157.

McKeown, B., \& Thomas, D. (1988). Q-Methodology. CA: Sage.

Moss, T. (2009). Intermediaries and the governance of sociotechnical networks in transition. Environment and Planning A, 41, 1480-1495. doi:10.1068/a4116 
Mouffe, C. (2005). On the political. London: Routledge.

Mullen, B., \& Hu, L. (1989). Perceptions of ingroup and outgroup variability: A meta-analytic integration. Basic and Applied Social Psychology, 10, 233252. doi:10.1207/s15324834basp1003_3

Nancarrow, B. E., Leviston, Z., Po, M., Porter, N. B., \& Tucker, D. I. (2008). What drives communities' decisions and behaviours in the reuse of wastewater. Water Science \& Technology, 57, 485-492. doi:10.2166/wst.2008.160

National Research Council. (1996). Understanding risk: Informing decisions in a democratic society. Washington DC: National Academy Press.

Niemeyer, S., Petts, J., \& Hobson, K. (2005). Rapid climate change and society: Assessing responses and thresholds. Risk Analysis, 25, 14431456. doi:10.1111/j.1539-6924.2005.00691.x

Peters, E., \& Slovic, P. (1996). The role of affect and worldviews as orienting dispositions in the perception and acceptance of nuclear power. Journal of Applied Social Psychology, 26, 1427-1453. doi:10.1111/j.15591816.1996.tb00079.x 
Po, M., Kaercher, J. D., \& Nancarrow, B. E. (2003). Literature review of factors influencing public perceptions of water reuse. Perth: CSIRO Land and Water.

Previte, J., Pini, B., \& Haslam-McKenzie, F. (2007). Q methodology and rural research. Sociologia Ruralis, 47, 135-147. doi:10.1111/j.14679523.2007.00433.x

Public Utilities Board. (2008). NEWater. [Electronic Resource], retrieved $24^{\text {th }}$ August 2009 from http://www.pub.gov.sg/NEWater/Pages/default.aspx.

Raadgever, G. T., Mostert, E., \& van de Giesen, N. C. (2008). Identification of stakeholder perspectives on future flood management in the Rhine basin using Q methodology. Hydrology and Earth System Sciences, 12, 10971109.

Radandt, S., \& Renn, O. (2008). New emerging risks. In H. J. Bischoff (Ed.), Risks in modern society. (pp. 259-283). BV: Springer Science+Business Media.

Renn, O. (2004). Perception of risks. Toxicology Letters, 149, 405-413. doi:10.1016/.toxlet.2003.12.051 
Robbins, P., \& Krueger, R. (2000). Beyond bias? The promise and limits of $Q$ method in human geography. Professional Geographer, 52, 636-648. doi:10.1111/0033-0124.00252

Roberts, G. (2008, November 19). Anna Bligh water down her recycling plan. The Australian, retrieved September 19, 2009, from http://www.theaustralian.news.com.au/story/0,25197,246736405013945,00.html.

Rose, N. (1999). The politics of life itself. Theory, Culture \& Society, 18, 1-30. doi:10.1177/02632760122052020

Ross, L. (1977). The intuitive psychologist and his shortcomings: Distortions in the attribution process. In L. Berkowitz (Ed.), Advances in experimental social psychology (vol. 10, pp. 173-220). New York: Academic Press.

Ross, V. (2005). The determinants of trust and satisfaction with drinking water quality. Perth: CSIRO Land and Water.

Russell, S., \& Lux, C. (2009). Getting over yuck: Moving from psychological to cultural and sociotechnical analyses of responses to water recycling. Water Policy, 11, 21-35. doi:10.2166/wp.2009.007 
Domain-based perceptions of risk

Schmolck, P., 2002. PQMethod 2.11. Downloaded from http://www.rz.unibwmuenchende/ p41bsmk/qmethod/.

Schofield, B. (2002). Partners in power: Governing the self-sustaining community. Sociology, 36, 663-683. doi:10.1177/0038038502036003009

Siegrist, M. (2002). The influence of trust and perceptions of risks and benefits on the acceptance of gene technology, Risk Analysis, 20(2), 195-204. doi:10.1111/0272-4332.202020

Simmons, P., \& Walker, G. (1999). Tolerating risk: Policy principles and public perceptions. Risk Decision and Policy, 4(3), 179-190.

Slovic, P. (2000). The perception of risk. London: Earthscan.

Slovic, P. (1987). Perception of risk. Science, 236, 280-285. doi:10.1126/science.3563507

Stainton-Rogers, R. (1998). Q methodology. In J. A. Smith, R. Harre and L. Van Langenhove (Eds.), Rethinking methods in psychology (pp. 178192). London: Sage.

Stenekes, N., Colebatch, H. K., Waite, T. D., \& Ashbolt, N. J. (2006). Risk and 
Domain-based perceptions of risk

governance in water recycling: Public acceptance revisited. Science, Technology \& Human Values, 31, 107-134. doi:10.1177/0162243905283636

Swedeen, P. (2006). Post-normal science in practice: A Q study of the potential for sustainable forestry in Washington State, USA. Ecological Economics, 57, 190-208. doi:10.1016/j.ecolecon.2005.04.003

Sztompka, P. (1999). Trust: A sociological theory. Cambridge: Cambridge University Press.

Tuler, S., \& Webler, T. (2009). Stakeholder perspectives about marine oil spill response objectives: A comparative $Q$ study of four regions. Journal of Contingencies and Crisis Management, 17, 95-107. doi:10.1111/j.14685973.2009.00568.x

Tversky, A., \& Kahneman, D. (1981). The framing of decisions and the psychology of choice. Science, 211, 435-438.

doi:10.1126/science. 7455683

Venables, D., Pidgeon, N., Simmons, P., Henwood, K., \& Parkhill, K. (2009). Living with nuclear power: A Q-method study of local community perceptions. Risk Analysis, 29, 1089-1104. doi:10.1111/j.15396924.2009.01259.x 
Walker, I., Broderick, P., \& Correia, H. (2007). Conceptions and misconceptions: Social representations of medically assisted reproduction. In G. Moloney and I. Walker (Eds.), Social representations and identity: Content, process, and power. NY: Palgrave Macmillan.

Walker, G., \& Shove, E. (2008). Ambivalence, sustainability and the governance of socio-technical transitions. In J. Newig, J-P, Voß, \& J. Monstadt (Eds.), Governance for sustainable development: Coping with ambivalence, uncertainty and distributed power (pp. 21 - 33). London: Routledge.

Water Corporation. (2008). Kwinana water reclaimation plant, retrieved $24^{\text {th }}$ August 2009 from http://www.watercorporation.com.au/ files/PublicationsRegister/7/kwrpbrochure.pdf.

Warner, W. S. (June 1999). The influence of religion on blackwater treatment. Paper presented at Managing the Wastewater Resource Conference, Norway.

Water Corporation. (2009). Water forever: Directions for our water future draft plan. Perth: Water Corporation.

Water Futures Toowoomba. (2006). Water futures voted down, retrieved 14th August 2009 from 
Domain-based perceptions of risk

http://www.toowoombawater.com.au/index.php?option=com content\&tas $\underline{k=v i e w \& i d=204 \& I t e m i d=1}$

Yee, W. M. S., Traill, W. B., Lusk, J. L., Jaeger, S. R., House, L., \& Moore, M. (2008). Determinants of consumers' willingness to accept GM foods.

International Journal of Biotechnology, 10, 240-259.

doi:10.1504/IJBT.2008.018356 
Domain-based perceptions of risk

\section{Tables}


Domain-based perceptions of risk

Table 1. Community Q-sort and technical experts' perceptions of community Q-sort along with their respective factor rankings (factor arrays)

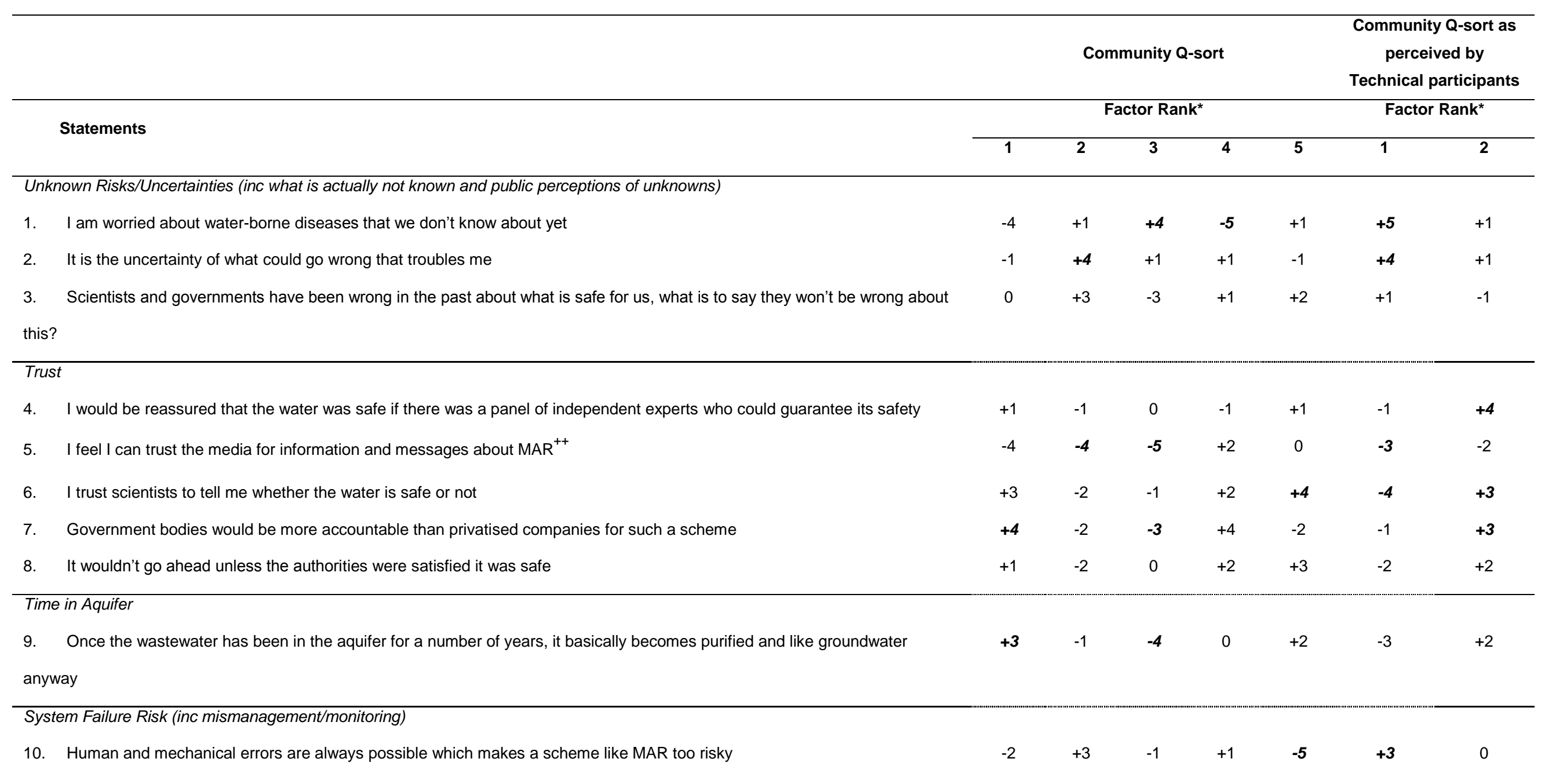




\section{Domain-based perceptions of risk}

11. A big risk with MAR is that the aquifer could become contaminated and nothing could be done about it. ${ }^{++}$

12. I am concerned about something going wrong such as breakdowns or something not working properly ${ }^{++}$

$\begin{array}{lllllll}-1 & +2 & +5 & +4 & -4 & +2 & +1 \\ -1 & +2 & 0 & +5 & 0 & +2 & +1\end{array}$

Management (inc scientific, policy and infrastructure management and knowledge)

13. I believe there is enough knowledge around about water testing, disease minimisation and harm reduction that MAR will not be a problem ${ }^{++}$

14. A main management priority should be to reduce industrial emissions and waste entering the water system before it becomes recycled water ${ }^{++}$

15. There needs to be strict legal and legislative requirements to make sure that the system is managed well

Relative/Competitive Risk (risk compared to other risks/other water sources)

16. I don't have a problem with MAR

17. People are exposed to so many risks everyday that the risk of MAR is too small to worry about

18. People don't really know what comes out of their tap now, so what's the difference if they put treated wastewater in it or not? ${ }^{++}$

Political Risk (inc risk to political domain, community backlash)

19. Political interests and processes could compromise the MAR scheme ${ }^{+++}$

Personal Health Risk (inc family health risk, and personal cumulative health risk)
20. My biggest concern is the health effects of drinking the recycled water ${ }^{++}$
21. I am worried about an outbreak of diseases and other illnesses
22. I am concerned about a build-up of chemicals and toxins in my body over time

\begin{tabular}{ccccccc}
-4 & +3 & +5 & 0 & +3 & +5 & +4 \\
-3 & +2 & +1 & -2 & 0 & +4 & +1 \\
-3 & +1 & +2 & -1 & +1 & +5 & +2 \\
\hline
\end{tabular}

Population Health Risks (include comments from Family Case study re risk to pop.) 


\section{Domain-based perceptions of risk}

23. I am concerned about the impact of the water on reproductive health and fertility ${ }^{++}$

24. I am worried about the effects from so called 'gender bending' chemicals ${ }^{++}$

Intergenerational Issues (inc cumulative intergenerational issues)

25. I am worried about how this might effect generations to come ${ }^{++}$

26. I am worried about the effects of the water on unborn babies and young children ${ }^{++}$

\begin{tabular}{llllllll}
-4 & 0 & +2 & -1 & 0 & +3 & +3 \\
\hline
\end{tabular}

Aesthetics
27. I am concerned that MAR will make the water taste and/or smell bad

Geographical Location and Fairness

28. I would be unhappy if I had to drink it and others didn't ${ }^{++}$

Fairness (General)

29. Those who pollute or use the water the most should have to use recycled wastewater before anyone else ${ }^{++}$ Financial Risk

30. If you put enough money into MAR, you could overcome just about any issue or risk ${ }^{++}$

31. We run the risk of paying way too much to get the water treated to a level that the community will accept. ${ }^{+}$

32. Government should be looking for water options that are the safest, not the cheapest ${ }^{++}$

$-2$

$+2$

$-2$

$\begin{array}{llllll}-1 & 0 & -1 & -5 & +1 & +3\end{array}$

Environmental (inc Risk)

33. I am concerned about the environmental impact on the aquifer

34. Given that we are already using water from the underground aquifers we should be replenishing it with something like recycled water

35. If the water is clean enough for us to drink then it will be clean enough for the environment

$\begin{array}{ccccccc}0 & -3 & -1 & 0 & +4 & -4 & -4 \\ -1 & 0 & -3 & -1 & -1 & -1 & -5 \\ +2 & +4 & 1 & -2 & 0 & +2 & +1\end{array}$

$\begin{array}{lllllll}0 & +1 & +2 & +2 & -2 & +1 & -2 \\ +4 & -1 & +1 & -3 & +2 & -2 & +2 \\ +3 & 0 & +1 & +3 & +4 & 0 & -2\end{array}$

$\begin{array}{lllllll}0 & +1 & +2 & +2 & -2 & +1 & -2 \\ +4 & -1 & +1 & -3 & +2 & -2 & +2 \\ +3 & 0 & +1 & +3 & +4 & 0 & -2\end{array}$




\section{Domain-based perceptions of risk}

36. I am concerned that the MAR process will be too energy intensive ${ }^{+}$

Perceptions of Community Response

37. Scientists base their decision-making on fact, community base their decisions on feeling ${ }^{++}$

38. If scientists can't agree on many things, how can the community be expected to agree?

39. We don't have the time to wait till the entire community is happy with the level of risk in drinking treated wastewater before it proceeds

40. The community do not have the required expertise or information to make a decision about $\mathrm{MAR}^{++}$

41. I support it, but you will have a hard time convincing others to use it $^{++}$

Chemical/Toxicological Risk

42. I have every faith in filtration. If you use enough filtration then even miniscule things can be removed ${ }^{++}$

43. You can't possibly account for all the different things that people flush down their toilets ${ }^{++}$

44. It is extremely unlikely that scientists can know how the different chemicals in recycled wastewater will react together ${ }^{++}$ Emotion

45. The thought of drinking sewage disgusts $\mathrm{me}^{++}$

Voluntary versus Imposed Risk

46. If people are not happy with drinking recycled water they should go out and buy bottled water.

47. There is a difference between choosing to take risks and having risks imposed on us like this would be ${ }^{++}$

Tolerability and Resignation to Risk

48. If I was told it was safe to drink I would probably just get used to drinking it ${ }^{++}$
$0 \quad 0$

0

0

$+1$

$+4$

0

$+2$

$-4+2$

$+3$

0

$\begin{array}{lllllll}+3 & -2 & +3 & +5 & -1 & 0 & 0\end{array}$

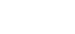

$+$

$+2 \quad-4 \quad-2 \quad-1$

$-1+$

$-3$

$+1$

-

$-5$

$-5$

$\begin{array}{ccccccc}0 & -2 & -4 & -4 & -4 & -5 & 0 \\ -1 & 2 & -2 & +2 & -2 & +2 & 0\end{array}$

$-4$

$-2$

0

$+3$

$-3$




\section{Domain-based perceptions of risk}

49. My life is too busy and there are too many other things to think about that I would probably just tolerate it even though I didn't like it.

50. I would rather drink recycled water than live with the anxiety that we could run out of water to drink.

51. There is controversy surrounding the use of recycled wastewater because it is a new concept ${ }^{++}$

52. I believe it is going to happen anyway, regardless of how I feel about it.

Alternative Futures

53. We need to focus on behaviour change and reducing water use before we look at other solutions ${ }^{++}$

54. I think that other solutions are a better source of drinking water for WA than MAR (e.g., rainwater tanks, and/or home water recycling, Ord River pipeline, desalination, SW Yarragadee) ${ }^{++}$

55. Water is too cheap and should cost more so that people don't waste it.

56. The real issue is controlling population growth, otherwise we will always be searching for more and more water ${ }^{++}$

57. I would prefer a scheme where recycled water was stored separately from our other drinking water supplies.

Perceptions of Abundant Supply

58. Recycling wastewater will just encourage people to use more water anyway ${ }^{++}$

59. WA is managing its water well enough to not need wastewater recycling.

60. I think it is safe as other countries have been drinking recycled water for a long time with no problems.

61. As a developed country, we have the technology and the finances to not have a water system that means we're drinking recycled sewage.

62. This is a fundamental public issue that needs more community debate before a decision is made.

\begin{tabular}{ccccccc}
+1 & 0 & +1 & -3 & -1 & -3 & +3 \\
0 & 0 & -4 & -5 & -5 & 0 & -3 \\
0 & +3 & +3 & -3 & -3 & +1 & -1 \\
\hline
\end{tabular}




\section{Domain-based perceptions of risk}

${ }^{++}$refers to the consensus statements for Technical perceptions of Community Q-sort 
Domain-based perceptions of risk

Table 2. Technical expert statements and their factor rankings (factor arrays)

\begin{tabular}{|c|c|c|c|c|}
\hline \multirow{2}{*}{ Statement } & \multicolumn{4}{|c|}{ Factor Rank* } \\
\hline & 1 & 2 & 3 & 4 \\
\hline \multicolumn{5}{|l|}{ Unknown Risks/Uncertainties (inc what is actually not known and public perceptions of unknowns) } \\
\hline 1. I am worried about water-borne diseases that we don't know about yet. & -4 & +2 & +2 & -2 \\
\hline 2. It is the uncertainty of what could go wrong that troubles me. & -3 & +4 & +2 & 0 \\
\hline 3. Scientists and governments have been wrong in the past about what is safe for us, what is to say they won't be wrong about this? & -1 & +4 & 0 & 0 \\
\hline \multicolumn{5}{|l|}{ Trust } \\
\hline 4. I would be reassured that the water was safe if there was a panel of independent experts who could guarantee its safety. & +3 & -3 & -2 & +5 \\
\hline 5. I feel I can trust the media for information and messages about MAR. & -4 & -5 & -2 & -5 \\
\hline 6. I trust scientists to tell me whether the water is safe or not. & +3 & -3 & -3 & -3 \\
\hline 7. Government bodies would be more accountable than privatised companies for such a scheme. & +2 & +1 & 0 & +3 \\
\hline 8. It wouldn't go ahead unless the authorities were satisfied it was safe. & +4 & -3 & -3 & +1 \\
\hline \multicolumn{5}{|l|}{ Time in Aquifer } \\
\hline 9. Once the wastewater has been in the aquifer for a number of years, it basically becomes purified and like groundwater anyway. & +5 & -1 & -2 & +1 \\
\hline \multicolumn{5}{|l|}{ System Failure Risk (inc mismanagement/monitoring) } \\
\hline 10. Human and mechanical errors are always possible which makes a scheme like MAR too risky. & -1 & +3 & 0 & +1 \\
\hline 11. A big risk with MAR is that the aquifer could become contaminated and nothing could be done about it. & -2 & +3 & +3 & +4 \\
\hline 12. I am concerned about something going wrong such as breakdowns or something not working properly. & -2 & +4 & +1 & +3 \\
\hline \multicolumn{5}{|l|}{ Management (inc scientific, policy and infrastructure management and knowledge) } \\
\hline 13. I believe there is enough knowledge around about water testing, disease minimisation and harm reduction that MAR will not be a problem. & +3 & -2 & -1 & -4 \\
\hline
\end{tabular}


Domain-based perceptions of risk

14. A main management priority should be to reduce industrial emissions and waste entering the water system before it becomes recycled water.

15. There needs to be strict legal and legislative requirements to make sure that the system is managed well.

0

$+5$

Relative/Competitive Risk (risk compared to other risks/other water sources)

16. I don't have a problem with MAR.

17. People are exposed to so many risks everyday that the risk of MAR is too small to worry about.

18. People don't really know what comes out of their tap now, so what's the difference if they put treated wastewater in it or not? Political Risk (inc risk to political domain, community backlash)

19. Political interests and processes could compromise the MAR scheme.

Personal Health Risk (inc family health risk, and personal cumulative health risk)

20. My biggest concern is the health effects of drinking the recycled water.

21. I am worried about an outbreak of diseases and other illnesses.

22. I am concerned about a build-up of chemicals and toxins in my body over time.

Population Health Risks (include comments from Family Case study re risk to pop.)

23. I am concerned about the impact of the water on reproductive health and fertility.

24. I am worried about the effects from so called 'gender bending' chemicals.

Intergenerational Issues (inc cumulative intergenerational issues)

25. I am worried about how this might effect generations to come.

26. I am worried about the effects of the water on unborn babies and young children

Aesthetics

27. I am concerned that MAR will make the water taste and/or smell bad.

Geographical Location and Fairness

28. I would be unhappy if I had to drink it and others didn' $\mathrm{t}^{+}$

$+1 \quad+3 \quad+3$

$+3$ 


\section{Domain-based perceptions of risk}

Fairness (General)

29. Those who pollute or use the water the most should have to use recycled wastewater before anyone else.

Financial Risk

30. If you put enough money into MAR, you could overcome just about any issue or risk.

31. We run the risk of paying way too much to get the water treated to a level that the community will accept.

32. Government should be looking for water options that are the safest, not the cheapest ${ }^{+}$

$\begin{array}{cccc}+3 & -5 & 1 & -4 \\ 0 & -2 & +3 & -1 \\ 0 & 0 & -2 & +1\end{array}$

Environmental (inc Risk)

33. I am concerned about the environmental impact on the aquifer.

34. Given that we are already using water from the underground aquifers we should be replenishing it with something like recycled water.

35. If the water is clean enough for us to drink then it will be clean enough for the environment.

36. I am concerned that the MAR process will be too energy intensive.

\section{Perceptions of Community Response}

37. Scientists base their decision-making on fact, community base their decisions on feeling.

38. If scientists can't agree on many things, how can the community be expected to agree? ${ }^{+}$

39. We don't have the time to wait till the entire community is happy with the level of risk in drinking treated wastewater before it proceeds.

40. The community do not have the required expertise or information to make a decision about MAR.

41. I support it, but you will have a hard time convincing others to use it.

$\begin{array}{rrrr}-2 & +1 & +3 & +5 \\ +4 & 0 & +2 & +4 \\ +1 & 0 & +1 & -4 \\ 0 & 0 & +4 & -3\end{array}$

Chemical/Toxicological Risk

42. I have every faith in filtration. If you use enough filtration then even miniscule things can be removed.

43. You can't possibly account for all the different things that people flush down their toilets.

44. It is extremely unlikely that scientists can know how the different chemicals in recycled wastewater will react together. Emotion 


\section{Domain-based perceptions of risk}

45. The thought of drinking sewage disgusts me.

Voluntary versus Imposed Risk

46. If people are not happy with drinking recycled water they should go out and buy bottled water.

47. There is a difference between choosing to take risks and having risks imposed on us like this would be.

$\begin{array}{cccc}-2 & -5 & 1 & 0 \\ +1 & +2 & -1 & 0 \\ +1 & 0 & -5 & -2 \\ -1 & -1 & -5 & -2 \\ +1 & 0 & -1 & -1 \\ +2 & +1 & +1 & +2 \\ -1 & +1 & -1 & 0\end{array}$

Alternative Futures

53. We need to focus on behaviour change and reducing water use before we look at other solutions ${ }^{+}$

54. I think that other solutions are a better source of drinking water for WA than MAR (e.g., rainwater tanks, and/or home water recycling, Ord River pipeline, desalination, SW Yarragadee).

55. Water is too cheap and should cost more so that people don't waste it ${ }^{+}$

56. The real issue is controlling population growth, otherwise we will always be searching for more and more water.

57. I would prefer a scheme where recycled water was stored separately from our other drinking water supplies. Perceptions of Abundant Supply through MAR

58. Recycling wastewater will just encourage people to use more water anyway.

$\begin{array}{cccc}0 & +2 & +4 & 0 \\ 0 & -1 & -2 & 0 \\ +5 & 0 & +4 & +1 \\ +1 & -1 & +5 & -4 \\ -5 & +2 & +5 & 0\end{array}$

59. WA is managing its water well enough to not need wastewater recycling

Societal Issues 


\section{Domain-based perceptions of risk}

60. I think it is safe as other countries have been drinking recycled water for a long time with no problems.

61. As a developed country, we have the technology and the finances to not have a water system that means we're drinking recycled sewage.

62. This is a fundamental public issue that needs more community debate before a decision is made. ${ }^{+}$

${ }^{*}$ Bolded and italicised figures represent statements that are important in order to distinguish one particular factor from all the remaining factors ${ }^{+}$refers to the consensus statements found in the technical expert Q-sort 
Indirect Potable Reuse: MAR - Community's sort $(n=37)$

\begin{tabular}{|c|c|c|c|c|}
\hline $\begin{array}{c}\text { Factor } 1 \quad(n=17) \\
23 \% \text { Variance } \\
\text { CONFIDENT }\end{array}$ & $\begin{array}{c}\text { Factor } 2(n=7) \\
13 \% \text { Variance } \\
\text { SCEPTICAL }\end{array}$ & $\begin{array}{c}\text { Factor } 3 \quad(\mathrm{n}=3) \\
7 \% \text { Variance } \\
\text { PESSIMISTIC }\end{array}$ & $\begin{array}{c}\text { Factor } 4 \quad(n=2) \\
7 \% \text { Variance } \\
\text { SUSPICIOUS }\end{array}$ & $\begin{array}{c}\text { Factor } 5 \quad(n=3) \\
7 \% \text { Variance } \\
\text { TRUSTING }\end{array}$ \\
\hline $\begin{array}{l}{ }^{*} \text { Accepting } \\
\text { * Belief in } \\
\text { accountability of } \\
\text { government } \\
{ }^{*} \text { Requires strict } \\
\text { regulation } \\
\text { * Confident in } \\
\text { science } \\
{ }^{*} \text { No health } \\
\text { concerns } \\
{ }^{*} \text { Pragmatic - } \\
\text { replenish the } \\
\text { aquifer; need for } \\
\text { the source; lacks } \\
\text { emotion }\end{array}$ & $\begin{array}{l}\text { * Not accepting } \\
\text { * Sceptical of } \\
\text { science, technology } \\
\text { and governing } \\
\text { systems } \\
\text { * Requires safe/safer } \\
\text { source options } \\
{ }^{*} \text { Future uncertainty } \\
\text { * Reduce water use } \\
\text { * Requires } \\
\text { community input and } \\
\text { debate }\end{array}$ & $\begin{array}{l}{ }^{*} \text { Accepting/unsure } \\
\text { * } \text { Lacks confidence in } \\
\text { accountability of } \\
\text { government } \\
{ }^{*} \text { Strong health } \\
\text { concerns } \\
{ }^{*} \text { Risk to aquifer } \\
\text { * Doubt about } \\
\text { alternative sources } \\
\text { * Lacks confidence in } \\
\text { community decision } \\
\text { making }\end{array}$ & $\begin{array}{l}\text { * Unsure } \\
\text { * Belief in } \\
\text { accountability of } \\
\text { government } \\
\text { * Requires strict } \\
\text { regulation } \\
\text { * Faith in scientific } \\
\text { fact } \\
\text { " Concerned about } \\
\text { system failure } \\
\text { " Concerned about } \\
\text { 'gender bending' } \\
\text { chemicals } \\
\text { * Not concerned } \\
\text { about long term } \\
\text { health effects }\end{array}$ & $\begin{array}{l}{ }^{*} \text { Accepting } \\
\text { * Indifferent to } \\
\text { need for strict } \\
\text { regulation } \\
{ }^{*} \text { Confident in } \\
\text { science } \\
{ }^{*} \text { Rejection of } \\
\text { system failure } \\
{ }^{*} \text { Belief that risks } \\
\text { can be overcome } \\
\text { with sufficient } \\
\text { funding } \\
\text { * Emotive about } \\
\text { drinking the } \\
\text { water } \\
\text { * Faith in } \\
\text { community } \\
\text { knowledge }\end{array}$ \\
\hline
\end{tabular}

Indirect Potable Reuse: MAR - Technical experts' sort ( $n=20)$

\begin{tabular}{|c|c|c|c|}
\hline $\begin{array}{c}\text { Factor } 1 \quad(n=10) \\
27 \% \text { Variance } \\
\text { CONFIDENT }\end{array}$ & $\begin{array}{c}\text { Factor } 2 \quad(n=5) \\
18 \% \text { Variance } \\
\text { SCEPTICAL }\end{array}$ & $\begin{array}{c}\text { Factor } 3(n=1) \\
10 \% \text { Variance } \\
\text { DEFIANT }\end{array}$ & $\begin{array}{c}\text { Factor } 4(\mathrm{n}=2) \\
10 \% \text { Variance } \\
\text { DOUBTFUL }\end{array}$ \\
\hline $\begin{array}{l}\text { * Accepting } \\
{ }^{*} \text { Confident in } \\
\text { science, } \\
\text { knowledge and } \\
\text { governing } \\
\text { authorities } \\
{ }^{*} \text { Requires strict } \\
\text { regulation } \\
{ }^{*} \text { Belief that risks } \\
\text { can be overcome } \\
\text { with sufficient } \\
\text { funding } \\
{ }^{*} \text { No health } \\
\text { concerns } \\
{ }^{*} \text { Pragmatic - } \\
\text { replenish aquifer; } \\
\text { need for the } \\
\text { source; lacks } \\
\text { emotion }\end{array}$ & $\begin{array}{l}{ }^{*} \text { Not accepting/ } \\
\text { unsure } \\
\text { * Sceptical of } \\
\text { science, technology } \\
\text { and governing } \\
\text { systems } \\
\text { * Strong health } \\
\text { concerns } \\
\text { * Future uncertainty } \\
\text { * Risk to aquifer } \\
\text { * Faith in community } \\
\text { knowledge and need } \\
\text { for debate }\end{array}$ & $\begin{array}{l}\text { * Not Accepting } \\
\text { * Distrust of science } \\
\text { and governing } \\
\text { authorities } \\
{ }^{*} \text { No health concerns } \\
\text { * Risk to aquifer } \\
\text { * Concerned about } \\
\text { energy use } \\
\text { * Reduce water use } \\
\text { * Pay more for water } \\
\text { * Address population } \\
\text { growth }\end{array}$ & $\begin{array}{l}\text { *Unsure } \\
{ }^{*} \text { Belief in accountability of } \\
\text { government } \\
{ }^{*} \text { Requires strict regulation } \\
\text { * Little confidence in } \\
\text { science, technology and } \\
\text { knowledge } \\
{ }^{*} \text { Mild health concerns } \\
\text { * Concerned about aquifer } \\
\text { environment } \\
\text { * Can't wait for whole of } \\
\text { community acceptance } \\
{ }^{*} \text { Lacks confidence in } \\
\text { community decision making }\end{array}$ \\
\hline
\end{tabular}

Indirect Potable Reuse: MAR - Technical experts' perception of community sort $(n=14)$

Factor $1(n=11) \quad$ Factor $2(n=3)$ 
Domain-based perceptions of risk

\begin{tabular}{ll}
\hline \multicolumn{1}{c}{ 45\% Variance } & \multicolumn{1}{c}{$19 \%$ Variance } \\
CHALLENGING & \multicolumn{1}{c}{ RESISTANT } \\
\hline${ }^{*}$ Not Accepting & ${ }^{*}$ Unsure \\
${ }^{*}$ Requires strict & ${ }^{*}$ Belief in \\
regulation & accountability of \\
* Distrust of & government \\
scientists & ${ }^{*}$ Requires strict \\
${ }^{*}$ Doubts that & regulation \\
science or money & ${ }^{*}$ Trust in scientists \\
could manage & and experts \\
risks & ${ }^{*}$ Money can't \\
${ }^{*}$ Concerned about & manage risks \\
system failure & ${ }^{*}$ Strong health \\
${ }^{*}$ Strong health & concerns \\
concerns & ${ }^{*}$ Can't pay too \\
${ }^{*}$ Future & much to get \\
uncertainty & acceptable \\
${ }^{*}$ Emotive about & treatment \\
drinking water & ${ }^{*}$ Not concerned \\
*Time to wait for & about energy use \\
whole of & ${ }^{*}$ Emotive about \\
community & drinking water \\
acceptance & ${ }^{*}$ Put up with anxiety \\
& of running out of \\
& water \\
\hline
\end{tabular}

